\title{
BMJ Open Clinical impact of lifestyle interventions for the prevention of diabetes: an overview of systematic reviews
}

\author{
Lara Howells, ${ }^{1}$ Besma Musaddaq, ${ }^{2}$ Ailsa J McKay, ${ }^{1}$ Azeem Majeed ${ }^{1}$
}

To cite: Howells L, Musaddaq B, McKay AJ, et al. Clinical impact of lifestyle interventions for the prevention of diabetes: an overview of systematic reviews. BMJ Open 2016;6: e013806. doi:10.1136/ bmjopen-2016-013806

- Prepublication history and additional material is available. To view please visit the journal (http://dx.doi.org/ 10.1136/bmjopen-2016013806).

\section{LH and BM contributed} equally to this work.

Received 8 August 2016 Revised 22 October 2016 Accepted 25 October 2016

\section{CrossMark}

\begin{abstract}
${ }^{1}$ Department of Primary Care and Public Health, Imperial College London, London, UK ${ }^{2}$ Royal Free Hospital, London, UK
\end{abstract}

Correspondence to Ailsa J McKay;

ailsa.mckay08@imperial.ac.uk

\section{ABSTRACT}

Objectives: To review the clinical outcomes of combined diet and physical activity interventions for populations at high risk of type 2 diabetes.

Design: Overview of systematic reviews (search dates April-December 2015).

Setting: Any level of care; no geographical restriction. Participants: Adults at high risk of diabetes (as per measures of glycaemia, risk assessment or presence of risk factors).

Interventions: Combined diet and physical activity interventions including $\geq 2$ interactions with a healthcare professional, and $\geq 12$ months follow-up.

Outcome measures: Primary: glycaemia, diabetes incidence. Secondary: behaviour change, measures of adiposity, vascular disease and mortality.

Results: 19 recent reviews were identified for inclusion; 5 with AMSTAR scores $<8$. Most considered only randomised controlled trials (RCTs), and RCTs were the major data source in the remainder. Five trials were included in most reviews. Almost all analyses reported that interventions were associated with net reductions in diabetes incidence, measures of glycaemia and adiposity, at follow-up durations of up to 23 years (typically $<6$ ). Small effect sizes and potentially transient effect were reported in some studies, and some reviewers noted that durability of intervention impact was potentially sensitive to duration of intervention and adherence to behaviour change. Behaviour change, vascular disease and mortality outcome data were infrequently reported, and evidence of the impact of intervention on these outcomes was minimal. Evidence for age effect was mixed, and sex and ethnicity effect were little considered.

Conclusions: Relatively long-duration lifestyle interventions can limit or delay progression to diabetes under trial conditions. However, outcomes from more time-limited interventions, and those applied in routine clinical settings, appear more variable, in keeping with the findings of recent pragmatic trials. There is little evidence of intervention impact on vascular outcomes or mortality end points in any context. 'Real-world'

implementation of lifestyle interventions for diabetes prevention may be expected to lead to modest outcomes.

\section{Strengths and limitations of this study}

- Our wide, thorough and systematic search identified a large volume of recent work for consideration.

- Our work followed widely accepted methodological standards.

- We did not consider the quality of primary studies in detail but relied on the methodologies of individual systematic reviews.

- We were unable to consider outcomes not addressed in the systematic reviews considered.

- We did not systematically search for recent, relevant primary studies.

\section{INTRODUCTION}

Type 2 diabetes mellitus (T2DM) is a chronic disease characterised by insulin resistance and hyperglycaemia, associated with various macrovascular and microvascular complications, reduced quality of life and reduced life expectancy. ${ }^{1}$ The global prevalence of T2DM has risen rapidly over the past three to four decades, driven by similar prevalence trends for overweight/obesity, population ageing and changes to population ethnic composition. ${ }^{2-4}$ In 2014, estimated global diabetes prevalence among adults was $8.5 \%,{ }^{4}$ with estimates suggestive that $90 \%$ of these cases are T2DM. Global prevalence among adults is predicted to reach $9.9 \%$ by $2030,{ }^{5}$ in line with anticipated upwards trends in risk factors. The costs of diabetes are high. In 2012, 1.5 million deaths were attributed to the disease, and a further 2.2 million to hyperglycaemia. ${ }^{4}$ The lower bound of estimated global expenditure on diabetes for 2014 was $11 \%$ of total health expenditure, and this proportion and absolute spending are anticipated to increase alongside the ongoing upwards trends in disease burden.

From a primary prevention perspective, reducing the burden of disease due to diabetes will require implementation of interventions that will reverse overweight/obesity 
trends to the extent that this more than offsets the anticipated accumulation of risk predicted by changing population demographics. ${ }^{7}$ In some countries, lifestyle (diet and physical activity) education and supported behaviour change programmes for the population with intermediate hyperglycaemia are currently being considered as part of the solution. ${ }^{8-10}$ Trial data do suggest that such interventions can prevent or delay progression to T2DM. ${ }^{11-15}$ However, there is less evidence for impact on glycaemia outwith formal explanatory trial settings. ${ }^{16}$ There is also currently little evidence that such programmes impact on microvascular and macrovascular outcomes, ${ }^{15}{ }^{17}$ which is important as complications account for much of the morbidity and mortality associated with diabetes, and more than half of global diabetes expenditure. ${ }^{18}$ There have been many systematic reviews on this topic, and they do not all reach the conclusion that sufficient data are available to recommend the use of diabetes prevention programmes (DPPs) at this time. We have therefore aimed to conduct a systematic overview of these reviews, specifically aiming to address the following questions:

1. Do combined diet and physical activity interventions for those at high risk of diabetes impact on glycaemic control and diabetes incidence (primary outcomes)?

2. Do combined diet and physical activity interventions for those at high risk of diabetes impact on dietary and physical activity behaviours, measures of adiposity, microvascular/macrovascular risk, disease or events, quality-adjusted life years or mortality (secondary outcomes)?

3. Does the effect of combined diet and physical activity interventions on the above outcomes depend on participant age, sex or ethnicity?

4. Does the effect of combined diet and physical activity interventions on the above outcomes depend on the nature of the trial (explanatory vs pragmatic trial)?

\section{METHODS}

This overview was conducted according to the relevant aspects of the PRISMA guidance ${ }^{19}$ and the Cochrane Handbook of Systematic Reviews (Chapter 22: Overviews of reviews).$^{20}$ Following scoping searches, a review protocol was developed, describing the search strategy and methods for data collection and analysis.

\section{Search}

The population and intervention elements of the review questions (above) were used to generate search terms (see table 1), in turn used to identify associated subject headings within each database of interest, as relevant. No search terms based on comparators or outcomes were used. Systematic review search filters were chosen based on performance in published analyses (eg, 'meta-analys:.mp. OR search:.tw. OR review.pt.' was chosen for use in Embase based on the outcomes reported in ref. 18). ${ }^{21}$ Search strategies were trialled

\section{Table 1 Search terms}

\begin{tabular}{|c|c|c|c|c|}
\hline & $\mathbf{P}$ & I & 0 & $\mathbf{S}$ \\
\hline $\begin{array}{l}\text { Key terms } \\
\text { Additional } \\
\text { terms }\end{array}$ & $\begin{array}{l}\text { Intermediate hyperglyc*emia } \\
\text { Impaired glucose tolerance, } \\
\text { glucose tolerance impairment, } \\
\text { impaired glucose sensitivity, } \\
\text { glucose intolerance, } \\
\text { intermediate glyc*emic control, } \\
\text { impaired fasting glucose, } \\
\text { glucose dysregulation, impaired } \\
\text { fasting glyc*emia, pre*diabetes, } \\
\text { pre*diabetic, pre*diabetes state, } \\
\text { pre*diabetic state, latent } \\
\text { diabetes, latent diabetic, } \\
\text { borderline diabetes, borderline } \\
\text { diabetic, borderline HbA1c, } \\
\text { borderline hyperglyc*emia, } \\
\text { borderline h*emoglobin A1c, } \\
\text { borderline A1c, sub*diabetic } \\
\text { hyperglyc*emia, non*diabetic } \\
\text { hyperglyc*emia, diabetes } \\
\text { prevention }\end{array}$ & $\begin{array}{l}\text { Lifestyle } \\
\text { Life*style, non*pharmacological } \\
\text { intervention, diet, diet therapy, } \\
\text { nutrition, dietetics, dietician, } \\
\text { nutritionist, nutrition* counsel*ing, } \\
\text { dietary intake, healthy eating, } \\
\text { physical activity, exercise, physical } \\
\text { conditioning, sport, resistance } \\
\text { training, aerobics, work*out, } \\
\text { strength training, weight training, } \\
\text { prevention, preventive health } \\
\text { service, preventative health service, } \\
\text { preventive intervention, preventative } \\
\text { intervention, prevention programme, } \\
\text { prevention programme, risk } \\
\text { reduction, harm reduction, } \\
\text { behavio*r modification, behavio*r } \\
\text { change, behavio*r therapy, } \\
\text { diabetes education, health } \\
\text { education, health promotion, } \\
\text { community*based intervention, } \\
\text { community*based programme, } \\
\text { community*based programme }\end{array}$ & $\begin{array}{l}\text { No associated } \\
\text { terms used in } \\
\text { searches }\end{array}$ & $\begin{array}{l}\text { Study design } \\
\text { terms drawn } \\
\text { from previous } \\
\text { studies (see text } \\
\text { for details) }\end{array}$ \\
\hline
\end{tabular}

Population and intervention identifiers from research questions ('key terms') and database-derived and thesaurus-derived alternatives ('additional terms').

*Wildcard character. 
before use, to ensure that relevant articles identified during the scoping search would be returned from each database. Adaptations were made where necessary.

The identified search terms were used to search MEDLINE (via PubMed), Embase (via Ovid), Web of Science, The Cochrane Library, Centre for Reviews and Dissemination database, Joanna Briggs Institute database, EPPI-Centre Database of Promoting Health Effectiveness Reviews and CINAHL database between 16 April 2015 and 24 April 2015. The searches were updated between 22 November 2015 and 07 December 2015. An example database search strategy is provided in online supplementary appendix 1 . We searched review registries and Open Grey between the same dates. Diabetes Care, Diabetologia and Diabetic Medicine were hand-searched between 17 April 2015 and 27 April 2015, and again on 12 December 2015. The reference lists of included papers were also searched.

At this stage, no restrictions were placed on language of publication, publication type or publication status. However, we limited publication dates to post-1990 (no upper limit), in view of the relatively recent interest in lifestyle interventions for diabetes prevention and the need to retain relevance to the current healthcare context.

\section{Selection}

The overview inclusion/exclusion criteria are listed in table 2. We included systematic reviews of structured combined diet and physical activity interventions for adults at high risk of diabetes. High risk of diabetes was defined as impaired glucose tolerance, impaired fasting glucose and/or borderline HbAlc (by any established criteria-subject to variation given the time periods and geographical areas covered by the search), metabolic syndrome, overweight/obesity, presence of multiple cardiovascular risk factors and/or high diabetes-risk or cardiovascular-risk score outcome. The intervention was required to include $\geq 2$ interactions with a healthcare professional. Where additional (ie, non-lifestyle) interventions were investigated, we included the study so long as diet and physical activity interventions were analysed separately. We included studies where interventions with diet and/or physical activity components were analysed together, so long as combined diet and physical activity interventions applied to $\geq 75 \%$ of the number of primary studies included in the analyses of interest, and total n-number relevant to these analyses. Similarly, we required the duration of follow-up to be $\geq 12$ months for $\geq 75 \%$ of the number of studies included in the analyses of interest and total number of participants. Reviews considering single group and comparative studies were included, and we required at least 25 participants per treatment arm of each primary study (or $\mathrm{n} \geq 50$ for cohort studies) -at follow-up-for $\geq 75 \%$ of reviewed studies. Comparator groups were required to receive no/usual care or a lower intensity lifestyle intervention. Studies were classed as systematic reviews if they met the Centre for Reviews and Dissemination Database of Abstracts of Reviews of Effects criteria (see table 2) ${ }^{22}$ and included a clear statement of the clinical topic, description of evidence retrieval methods and sources, and at least one study that met minimum

Table 2 Inclusion and exclusion criteria

\section{Inclusion criteria}

$P \geq 18$ years

High risk of diabetes: impaired glucose tolerance, impaired fasting glucose and/or borderline $\mathrm{HbA1c}$ (by any established criteria-subject to variation given the time-periods and geographical areas covered by the search), metabolic syndrome, overweight/obesity, presence of multiple cardiovascular risk factors and/or high diabetes-risk or cardiovascular-risk score outcome

n-number for each treatment arm of each primary study $\geq 25$ for $\geq 75 \%$ of included studies

I $\geq 75 \%$ of primary studies assess combined diet and physical activity intervention involving $\geq 2$ interactions with a healthcare professional, and $\geq 75 \%$ of total review n-number received such an intervention

C No/usual care or lower intensity intervention (where relevant)

O Duration of follow-up $\geq 12$ months for $\geq 75 \%$ of the number of studies and total number of participants

S Systematic review as per Centre for Reviews and Dissemination Database of Abstracts of Reviews of Effects criteria, ${ }^{19}$ plus clear statement of the clinical topic, description of evidence retrieval methods and sources, and inclusion of at least one study that met minimum methodological standards for inclusion

Reviews considering single group and/or comparative studies included Review published post-1990

\section{Exclusion criteria}

Review limited to study of populations with previous gestational diabetes

Diet or physical activity intervention alone No face-to-face or telephone contact with healthcare professional Comparison with pharmacological or surgical intervention only

Review updated Non-English language review 
methodological standards for inclusion-as per additional guidance. ${ }^{21}{ }^{23}$ Where reviews had been updated, we included the most recent version only. Non-English language studies were excluded during selection, with the number of studies excluded for this reason recorded.

Two reviewers screened the titles and abstracts of the combined search results. Studies that potentially met the inclusion criteria at this point were subject to full review by two reviewers, with exclusions made according to the criteria above. Discrepancies in study selection were resolved by discussion and consensus decision.

\section{Data extraction and quality assessment}

Extraction of information about review aims, methods and results-including quality of evidence for outcomes presented-was achieved via structured data extraction proforma. The proforma was tested on a subset of papers, with changes made before final use in data collection. Additionally, information about the primary studies included in each review was recorded such that the extent of overlap between the sets of primary studies included in each review could be assessed. The data extraction was carried out by one reviewer and checked by a second reviewer, with discrepancies resolved by discussion and consensus decision. Two reviewers independently assessed the quality of each review using the AMSTAR criteria. ${ }^{24}$ Inconsistencies were resolved by discussion and consensus decision.

\section{Data synthesis}

Narrative synthesis methods were used. The review metadata were first summarised by tabulating the inclusion/ exclusion criteria, number of studies and participants involved, outcomes of interest assessed and quality assessment results. A matrix demonstrating the primary studies included in each review-and therefore the number of times each primary study had been included -was also developed.

The characteristics of the participants and interventions considered in each review were then also summarised via tabulation, and tables describing the review findings were produced for each outcome of interest, in turn. The consistency of direction and magnitude of any effect, across the different reviews, was considered for each outcome. Where inconsistencies were identified, the additional study data (ie, review methodology, overall population characteristics, outcome definitions and/or quality of studies) were examined for potential explanatory factors. The outcomes for the prespecified subgroups of interest were assessed in the same way. No exclusions were made on the basis of the study metadata, but these were used to consider the relative weight of each primary study in producing the outcomes reported (ie, the potential impact of inclusion of individual primary studies in multiple reviews), and a sensitivity analysis excluding studies with AMSTAR scores $<8$ was undertaken for each outcome.

\section{RESULTS}

The search produced 3969 papers for review. Figure 1 displays the handling of the search results. Nineteen studies were selected for inclusion. ${ }^{1}{ }^{16}{ }^{25-41}$ A list of the studies excluded at the stage of full-text review is available in online supplementary appendix 2.

\section{Study metadata}

The study metadata are summarised in online supplementary appendix 3. All reviews had been published between 2005 and 2016, and the majority (15/19) post-2010. All except one (Ashra et al, 2015) ${ }^{25}$ were peerreviewed journal articles. There was considerable overlap in primary studies between reviews. In particular, five trials were included in most reviews: the US Diabetes Prevention Programme (DPP), the Finnish Diabetes Prevention Study (DPS), the Indian Diabetes Prevention Programme (IDPP), the Da Qing study and a single-site UK-based trial (Oldroyd et al, 2006). ${ }^{42}$ Most reviews (13/ $19)$ included only RCTs. RCTs constituted the majority of studies included in all remaining reviews, and in several of these only the RCT data were used in meta-analysis.

Regarding inclusion/exclusion criteria, measures of glycaemia were the most frequently used indicators of high diabetes risk (16/19 reviews). Formal diabetes risk assessment, presence of metabolic syndrome, presence of obesity and/or presence of other T2DM risk factors were also used to indicate high risk (each used in three reviews).

\section{Quality assessment outcomes}

Summary quality assessment results are displayed in online supplementary appendix 3. AMSTAR checklist points were most frequently deducted for failing to state that grey literature had been searched or for omitting to provide a complete list of excluded studies. Five studies had an AMSTAR score of $\leq 7$ and were therefore excluded from sensitivity analyses (see above). ${ }^{26} 30343740$

\section{Interventions investigated in reviewed studies}

The nature and durations of interventions reviewed varied between studies. Details of the interventions reviewed in each case are summarised in online supplementary appendix 4 . Where reported (7/19 reviews), intervention duration ranged from 1 month to 10 years. Programme intensity, extent of group versus individual delivery, intervention settings, methods of delivery and diet and physical activity advice given were variable. Some interventions followed a fixed intensity approach, whereas others used an initial intensive phase, before an intermittent maintenance phase. Most of the physical activity programme components consisted of advice to increase aerobic physical activity, with variable use of structured or unstructured supervised physical activity sessions. Dietary components frequently involved advice on energy restriction, portion control and/or customised dietary counselling. 
Figure 1 Flow chart demonstrating handling of papers returned by search. Chart adapted from Moher et al. ${ }^{19}$ T2DM, type 2 diabetes mellitus; QALYS, quality-adjusted life years.

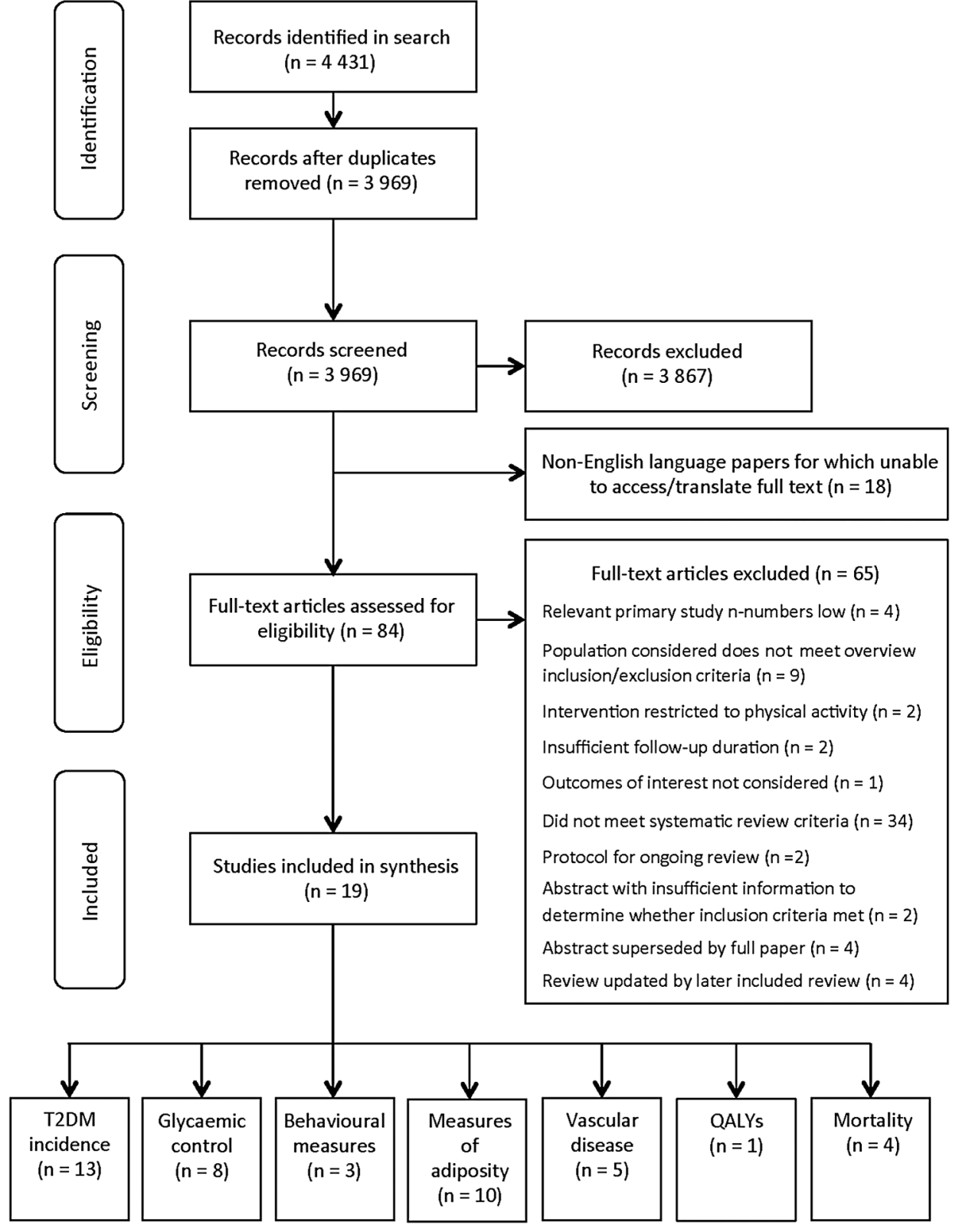

Where ranges were specified (15/19 reviews), follow-up durations ranged from 4 months to 20 years. In most of these reviews (11/15 cases), the minimum follow-up period was at least 1 year.

\section{Participant characteristics}

Participant characteristics are summarised in online supplementary appendix 4 . These relate to all participants in each review, some of which considered pharmacological and/or surgical interventions, as well as lifestyle options. Participant age was reported in all but one review, and variably summarised as a range, range of primary study-level means or overall review mean or median. Ranges extended from 20 to 79 years and mean/medians from 38 to 65 years. Similar summary gender measures were reported (available for 11 reviews), with the proportions of female participants in the reviewed studies (reported in 5 reviews) ranging from $0 \%$ to $100 \%$, and overall mean/median per cent female ranging from $34.7 \%$ to $66 \%$ (reported in five reviews). Summary measures of ethnicity were rarely available, although reviews often reported that samples were of diverse ethnic background. Summary baseline measures of body mass index (BMI) were reported in 10 reviews, with all primary study and review mean values reported $>24 \mathrm{~kg} / \mathrm{m}^{2}$, and the upper limit of primary study means reported being $37.4 \mathrm{~kg} / \mathrm{m}^{2}$.

\section{Intervention effects-primary outcomes}

Diabetes incidence

Incident diabetes was considered in 16 reviews, with reported outcomes drawing on 4-16 primary studies in each case (see table 3). Meta-analyses were run in 12 reviews, and all meta-analysis outcomes were indicative that intervention was associated with lower rates of progression to diabetes, with risk reductions generally in 
Table 3 Incident diabetes and additional glycaemia outcomes

\begin{tabular}{|c|c|c|}
\hline Author, publication date & $\begin{array}{l}\text { Number of studies } \\
\text { included in syntheses }\end{array}$ & Outcomes \\
\hline \multicolumn{3}{|l|}{ Incident diabetes } \\
\hline Ashra, 2015 & 11 studies & $\begin{array}{l}\text { Intervention associated with lower rate of progression to diabetes: } \\
\text { meta-analysis IRR }=0.74(95 \% \mathrm{Cl} 0.58 \text { to } 0.93)\end{array}$ \\
\hline Baker, 2011 & 7 studies & $\begin{array}{l}\text { Intervention associated with significantly lower incidence of T2DM } \\
\text { in all studies reviewed. RR reduction ranged from } 29 \% \text { to } 75 \% \text {. }\end{array}$ \\
\hline Balk, 2015 & 16 studies & $\begin{array}{l}\text { Intervention associated with lower rate of incident diabetes: } \\
\text { summary } \mathrm{RR}=0.59(95 \% \mathrm{Cl} 0.51 \text { to } 0.66)\end{array}$ \\
\hline Gillett, 2012 & $\begin{array}{l}5 \text { systematic reviews; } 9 \\
\text { RCTs }\end{array}$ & $\begin{array}{l}\text { Authors observed that lifestyle interventions were associated with } \\
\text { lower rates of progression to diabetes in most studies and } \\
\text { concluded that some diabetes can be prevented or delayed by } \\
\text { lifestyle interventions, with larger, longer term trials (the DPS, } \\
\text { DPP and Da Qing study) providing the best evidence. Some } \\
\text { evidence that this intervention effect was temporary was also } \\
\text { noted, as well as the DPS suggestion that adherence to lifestyle } \\
\text { change may be an important mediator of impact on diabetes risk. }\end{array}$ \\
\hline Glechner, 2015 & 5 studies & $\begin{array}{l}\text { Meta-analysis outcomes suggest intervention non-significantly } \\
\text { associated with lower risk of progression to T2DM at } 1 \text { year: } \\
\mathrm{RR}=0.60 \text { ( } 95 \% \mathrm{Cl} 0.35 \text { to } 1.05 ; 4 \text { studies). Evidence of significant } \\
\text { intervention effect on progression to diabetes at } 3 \text { years: RR=0.63 } \\
\text { ( } 0.51 \text { to } 0.79 ; 5 \text { studies). }\end{array}$ \\
\hline Hopper, 2011 & 4 studies & $\begin{array}{l}\text { In meta-analysis, intervention associated with lower rate of } \\
\text { progression to T2DM: } \mathrm{RR}=0.52(95 \% \mathrm{Cl} 0.46 \text { to } 0.58) \text {. }\end{array}$ \\
\hline $\begin{array}{l}\text { Merlotti, Morabito and } \\
\text { Pontiroli, } 2014\end{array}$ & 11 studies & $\begin{array}{l}\text { Intervention associated with lower rate of progression to diabetes: } \\
\text { meta-analysis } \mathrm{OR}=0.43(95 \% \mathrm{Cl} 0.35 \text { to } 0.52) \text {. }\end{array}$ \\
\hline $\begin{array}{l}\text { Merlotti, Morabito, Ceriani and } \\
\text { Pontiroli, } 2014\end{array}$ & 4 studies & $\begin{array}{l}\text { Intervention associated with lower rates of progression to } \\
\text { diabetes: meta-analysis } \mathrm{OR}=0.44(95 \% \mathrm{Cl} 0.36 \text { to } 0.52) \text {. }\end{array}$ \\
\hline Modesti, 2016 & 8 studies & $\begin{array}{l}\text { Intervention associated with lower rates of progression to } \\
\text { diabetes: meta-analysis OR=0.55 ( } 95 \% \mathrm{Cl} 0.44 \text { to } 0.70) \text {. }\end{array}$ \\
\hline Norris, 2005 & 5 studies & $\begin{array}{l}\text { Intervention associated with significantly lower cumulative } \\
\text { incidence of diabetes in three of the five trials reviewed (RR } \\
\text { reductions }=58 \%(95 \% \mathrm{Cl} 48 \text { to } 66), 51 \% \text { and } 58 \%) \text {. Trials in } \\
\text { which effect observed involved intensive, sustained, } \\
\text { multicomponent interventions. }\end{array}$ \\
\hline Orozco, 2008 & 8 studies & $\begin{array}{l}\text { Intervention associated with lower rates of progression to } \\
\text { diabetes: meta-analysis } \mathrm{RR}=0.63(95 \% \mathrm{Cl} 0.49 \text { to } 0.79) \text {. Similar } \\
\text { results when largest study (DPP; weight=26\%) excluded: } \\
\mathrm{RR}=0.69 \text { ( } 0.55 \text { to } 0.87) \text {. }\end{array}$ \\
\hline Santaguida, 2005 & 5 studies & $\begin{array}{l}\text { Significantly lower rates of progression to diabetes or higher rates } \\
\text { of reversion to normal glucose tolerance, observed in intervention } \\
\text { vs control arms of } 4 / 5 \text { trials. (NB. Number of studies considering } \\
\text { progression to diabetes specifically not described). ARR for } \\
\text { progression to diabetes ranged from } 1.6 \% \text { to } 7.1 \% \text {. RR reduction } \\
\text { for progression to diabetes in intervention, cf. control } \\
\text { scenario }=31-55 \% \text {. Observed NNT for } 1 \text { year to avoid one case of } \\
\text { diabetes }=14.2 \text { to } 62.5 \text {. In meta-analysis, RR of progression to } \\
\text { diabetes in intervention, cf. control arms }=0.54 \text { ( } 95 \% \mathrm{Cl} 0.42 \text { to } \\
0.70) \text {. }\end{array}$ \\
\hline Selph, 2015 & 6 studies & $\begin{array}{l}\text { Intervention associated with lower risk of progression to diabetes: } \\
\text { meta-analysis } \mathrm{RR}=0.55(95 \% \mathrm{Cl} 0.43 \text { to } 0.70) \text {. Similar results } \\
\text { when Da Qing study ( } 23 \text {-year follow-up) excluded: } \mathrm{RR}=0.53(0.44 \\
\text { to } 0.63) \text {. }\end{array}$ \\
\hline Shellenberg, 2013 & 7 studies & $\begin{array}{l}\text { Intervention associated with lower risk of progression to diabetes } \\
\text { at } 1 \text { year (meta-analysis } \mathrm{RR}=0.35,95 \% \mathrm{Cl} 0.14 \text { to } 0.85 \text {; four } \\
\text { studies), } 4 \text { years (RR=0.56, } 0.48 \text { to } 0.64 ; 2 \text { studies), } 6 \text { years } \\
\text { (RR=0.47, } 0.34 \text { to } 0.65 ; 3 \text { studies), and } 10 \text { years (RR=0.80, } 0.74 \\
\text { to } 0.88 ; \text { one study). Da Qing study not included in meta-analysis, } \\
\text { but noted that intervention associated with lower rates of } \\
\text { progression to diabetes at } 6 \text { and } 20 \text { years, in this study. }\end{array}$ \\
\hline
\end{tabular}


Table 3 Continued

\begin{tabular}{|c|c|c|}
\hline Author, publication date & $\begin{array}{l}\text { Number of studies } \\
\text { included in syntheses }\end{array}$ & Outcomes \\
\hline Stevens, 2015 & 16 studies & $\begin{array}{l}\text { In network meta-analysis (incorporating } 16 \text { lifestyle vs placebo/ } \\
\text { standard care studies) lifestyle intervention associated with lower } \\
\text { risk of progression to diabetes: } \mathrm{HR}=0.65(95 \% \mathrm{Cl} 0.56 \text { to } 0.74) \text {. }\end{array}$ \\
\hline Yoon, 2013 & 7 studies & $\begin{array}{l}\text { T2DM incidence ranged from } 3 \% \text { to } 46 \% \text { in the intervention } \\
\text { groups, cf. 9.3\% to } 67.7 \% \text { in the control groups. Significantly } \\
\text { lower T2DM incidence associated with intervention observed in 5/ } \\
7 \text { studies (RR reduction } 28.5 \% \text { to } 64.7 \% \text { ). In the sixth study, lower } \\
\text { diabetes incidence observed in the intervention vs control } \\
\text { scenario at 1-year follow-up, but not at 3-years or 5-years. In the } \\
\text { seventh study, intervention effect was observed only in the per } \\
\text { protocol analysis (ie, no effect observed in intention to treat } \\
\text { analysis). }\end{array}$ \\
\hline \multicolumn{3}{|r|}{ 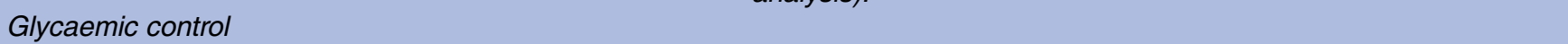 } \\
\hline \multirow[t]{2}{*}{ Ashra, 2015} & 16 studies & $\begin{array}{l}\text { No significant impact of intervention, cf. control condition } \\
\text { observed at } 12-18 \text { months: net } \mathrm{FPG} \text { difference }=-0.06 \mathrm{mmol} / \mathrm{L} \\
\text { ( } 95 \% \mathrm{Cl}-0.11 \text { to } 0.00 ; 16 \text { trials). Significant impact observed at } \\
>18 \text { months: net FPG difference }=-0.07 \mathrm{mmol} / \mathrm{L}(-0.13 \text { to }-0.02) \text {. }\end{array}$ \\
\hline & 10 studies & $\begin{array}{l}\text { No significant impact of intervention, cf. control condition } \\
\text { observed at } 12-18 \text { months (net } 2 \mathrm{~h}-\mathrm{OGT} \text { difference }=-0.28 \mathrm{mmol} / \\
\mathrm{L}, 95 \% \mathrm{Cl}-0.57 \text { to } 0.00 ; 10 \text { trials), or }>18 \text { months (difference= } \\
-0.52 \mathrm{mmol} / \mathrm{L},-1.05 \text { to } 0.01 ; 7 \text { studies). }\end{array}$ \\
\hline \multirow[t]{2}{*}{ Balk, 2015} & 6 studies & $\begin{array}{l}\text { Intervention associated with reversion to normoglycaemia: } \\
\text { meta-analysis summary } R R=1.53(95 \% \mathrm{Cl} 1.26 \text { to } 1.71) \text {. }\end{array}$ \\
\hline & 18 studies & $\begin{array}{l}\text { At follow-up closest to } 1 \text { year, summary net change in FPG } \\
\text { associated with intervention vs control condition }=-0.12 \mathrm{mmol} / \mathrm{L} \\
(-0.20 \text { to }-0.05 ; 17 \text { studies). Net change in } 2 \mathrm{~h}-\mathrm{OGT}= \\
-0.48 \mathrm{mmol} / \mathrm{L}(-0.86 \text { to }-0.17 ; 11 \text { studies) and net change in } \\
\mathrm{HbA}_{1 \mathrm{c}}=-0.08 \%(-0.12 \text { to }-0.04 ; 8 \text { studies). }\end{array}$ \\
\hline \multirow[t]{2}{*}{ Cardonna-Morrell, 2010} & 9 studies & $\begin{array}{l}\text { Authors concluded that the } 1 \text {-year FPG outcomes across nine } \\
\text { translational studies were in many cases similar to the DPP } \\
\text { outcomes, but that effect size was too small to be clinically } \\
\text { relevant. }\end{array}$ \\
\hline & 4 RCTs & $\begin{array}{l}\text { No observed significant net impact of intervention vs control } \\
\text { condition on } 12 \text {-month FPG (difference }=-0.19 \mathrm{mmol} / \mathrm{L} ; 95 \% \mathrm{Cl} \\
-0.44 \text { to } 0.06 ; 3 \text { trials) or } 2 \mathrm{~h}-\mathrm{OGT}(0.04 \mathrm{mmol} / \mathrm{L},-0.49 \text { to } 0.42 ; 2 \\
\text { RCTs). }\end{array}$ \\
\hline Gillett, 2012 & $\begin{array}{l}5 \text { systematic reviews; } 9 \\
\text { RCTs }\end{array}$ & $\begin{array}{l}\text { Authors conclude that most studies suggest intervention } \\
\text { associated with reversion to normal glucose tolerance }\end{array}$ \\
\hline Glechner, 2015 & 3 studies & $\begin{array}{l}\text { At } 1 \text {-year follow-up, intervention associated with significantly } \\
\text { lower FPG (meta-analysis }=-0.28 \mathrm{mmol} / \mathrm{L} ; 95 \% \mathrm{Cl}-0.47 \text { to } \\
-0.008 \text { ), and } 2 \mathrm{~h}-\mathrm{OGT}(-0.63 \mathrm{mmol} / \mathrm{L},-1.08 \text { to }-0.18 \text { ). Similar } \\
\text { outcomes observed at } 3 \text {-year follow-up (for } \mathrm{FPG}:-0.31 \mathrm{mmol} / \mathrm{L} \text {; } \\
-0.48 \text { to }-0.15 \text {; for OGT: }-0.68 \mathrm{mmol} / \mathrm{L} ; 95 \% \mathrm{Cl}-1.03 \text { to }-0.34 \text { ). }\end{array}$ \\
\hline Gong, 2015 & 7 studies & $\begin{array}{l}\text { Mean net } 2 \text {-OGT difference associated with lifestyle vs control } \\
\text { condition observed in meta-analysis }=-0.65 \mathrm{mmol} / \mathrm{L} ; 95 \% \mathrm{Cl} \\
-1.35 \text { to } 0.05\end{array}$ \\
\hline Norris, 2005 & 6 studies & $\begin{array}{l}\text { The six studies that reported on } \mathrm{HbA}_{1 \mathrm{c}} \text { were considered not to be } \\
\text { representative of all nine studies identified for review. Results } \\
\text { therefore not pooled, but effect of intervention ranged from } 0.0 \% \\
\text { to }-0.3 \% \text {. }\end{array}$ \\
\hline \multirow[t]{2}{*}{ Orozco, 2008} & 7 studies & $\begin{array}{l}\text { Meta-analysis of } 6 / 7^{*} \text { studies demonstrated significant impact of } \\
\text { intervention on FPG: net difference, cf. control condition= } \\
-0.19 \mathrm{mmol} / \mathrm{L}(95 \% \mathrm{Cl}-0.32 \text { to }-0.05) \text {. }\end{array}$ \\
\hline & 4 studies & $\begin{array}{l}\text { Meta-analysis of } 3 / 4^{*} \text { studies found no impact of intervention on } \\
2 \mathrm{~h}-\mathrm{OGT} \text { : net difference, cf. control condition }=-0.23 \mathrm{mmol} / \mathrm{L} \\
(-1.08 \text { to } 0.61) \text {. }\end{array}$ \\
\hline
\end{tabular}


Table 3 Continued

\begin{tabular}{|c|c|c|}
\hline Author, publication date & $\begin{array}{l}\text { Number of studies } \\
\text { included in syntheses }\end{array}$ & Outcomes \\
\hline Santaguida, 2005 & 5 studies & $\begin{array}{l}\text { Lifestyle intervention associated with significantly lower risk of } \\
\text { progression to diabetes, or higher rate of reversion to normal } \\
\text { glucose tolerance, in } 4 / 5 \text { trials reviewed (NB. number of studies } \\
\text { considering glucose tolerance specifically not described.). }\end{array}$ \\
\hline \multirow[t]{3}{*}{ Shellenberg, 2013} & 7 studies & $\begin{array}{l}\text { Intervention associated with significantly lower FPG at } 0.5- \\
4 \text { years follow-up: summary mean difference }=-0.28 \mathrm{mmol} / \mathrm{L}, 95 \% \\
\mathrm{Cl}-0.33 \text { to }-0.23 \text {. Authors concluded that data post- } 4 \text { years } \\
\text { follow-up insufficient to draw conclusions. }\end{array}$ \\
\hline & 5 studies & $\begin{array}{l}\text { Intervention associated with significantly lower } 2 \mathrm{~h}-\mathrm{OGT} \text { at } 1- \\
4 \text { years follow-up: summary mean difference }=-0.54,-1.06 \text { to } \\
-0.02 \text {. Again, data at post } 4 \text { years follow-up considered } \\
\text { insufficient to draw conclusions. }\end{array}$ \\
\hline & 3 studies & $\begin{array}{l}\text { No significant difference in } \mathrm{HbA} 1 \mathrm{c} \text { observed between intervention } \\
\text { and control groups at } 1-3 \text { years follow-up: summary mean } \\
\text { difference }=-0.10,-0.22 \text { to }-0.01 \text {. }\end{array}$ \\
\hline Zheng, 2015 & 12 studies & $\begin{array}{l}\text { Intervention associated with significantly lower } \mathrm{FPG} \text {, cf. control } \\
\text { condition: mean difference }=-0.22 \mathrm{mmol} / \mathrm{L}(95 \% \mathrm{Cl}-0.25 \text { to } \\
-0.18 ; 9 \text { studies). Also noted that the intervention effect } \\
\text { increased with intervention duration, with the effect among the } \\
\text { subgroup receiving the longest interventions }(\geq 2 \text { years duration) } \\
\text { demonstrating the highest subtotal effect: mean difference for this } \\
\text { subgroup }=-0.24 \mathrm{mmol} / \mathrm{L}(-0.43 \text { to }-0.05 ; 12 \text { studies). }\end{array}$ \\
\hline \multicolumn{3}{|c|}{$\begin{array}{l}\text { Synthesis outcomes related to glycaemia are listed for each review, as relevant, alongside the number of primary studies drawn on in the } \\
\text { associated syntheses. Italicised entries are those assigned AMSTAR scores <8, excluded from sensitivity analyses. } \\
\text { *Da Qing study not included in either meta-analysis due to cluster randomisation. } \\
\text { ARR, absolute risk reduction; DPP, Diabetes Prevention Programme; DPS, Diabetes Prevention Study; FPG, fasting plasma glucose; HbA1c, } \\
\text { glycated haemoglobin; IRR, incidence rate ratio; NNT, number needed to treat; RCT, randomised controlled trial; RR, relative risk; T2DM, type } \\
2 \text { diabetes mellitus; 2h-OGT, 2-hours oral glucose tolerance. }\end{array}$} \\
\hline
\end{tabular}

the region of $50-60 \%$. The outcomes of narrative syntheses agreed that intervention was associated with lower progression to diabetes in most studies. These syntheses additionally noted that the effects were more convincing in the larger, more intensive, longer term trials and that intervention effect could be transient. ${ }^{28} 3540$ One analysis suggested that adherence to lifestyle change might be an important mediator of sustained impact and potentially sensitive to the duration of intervention. ${ }^{28}$ Excluding reviews with AMSTAR scores $\leq 7 \quad(n=4)$ had little impact on overall outcomes.

\section{Glycaemic control}

Additional measures of glycaemia considered included measures of fasting glucose (seven reviews: seven meta-analyses), 2-hour oral glucose tolerance (2h-OGT; seven reviews: seven meta-analyses), HbAlc (three reviews; two meta-analyses, one narrative synthesis) and reversion to normoglycaemia (three reviews; one meta-analysis, two narrative syntheses) (see table 3). For fasting glucose measures, all but one meta-analysis suggested that interventions were associated with net reductions in glycaemia at follow-up. The lack of effect observed in one review may have been due to the study inclusion/exclusion criteria, which required that the primary studies were translations of the major diabetes prevention RCTs (ie, the DPP, Da Qing study, DPS or IDPP) into routine practice (and thus excluded the major larger-scale, longer term trials that tend to dominate the analyses in most reviews). ${ }^{16}$ This review similarly found no impact of the intervention on $2 \mathrm{~h}-\mathrm{OGT}^{16}{ }^{16}$ again out of keeping with the findings of other reviews. Only one other review observed no effect on 2h-OGT. ${ }^{25}$ This analysis was recently published and included a larger number of trials than the other reviews.

The clinical relevance of the effect sizes was queried in one review. ${ }^{16}$ Effect sizes were typically in the range $0.1-0.3 \mathrm{mmol} / \mathrm{L}$ for fasting glucose and $0.2-0.7 \mathrm{mmol} / \mathrm{L}$ for 2h-OGT (see table 3). A narrative synthesis of net intervention effect on HbAlc suggested this ranged from 0.0 to 0.3 percentage points, ${ }^{35}$ in keeping with corresponding meta-analysis outcomes that indicated intervention effects of $-0.08 \%(95 \%$ CI -0.12 to -0.04$)$ and $-0.10 \% \quad(-0.22$ to -0.01$){ }^{27} 38$ Again, exclusion of studies with AMSTAR scores $\leq 7 \quad(n=2)$ had little impact on general outcomes, which were largely consistent across reviews.

\section{Intervention effects-secondary outcomes Behaviour change}

Three reviews reported on the effects of interventions on dietary and/or physical activity behaviours (see table 4). Results were reportedly generally variable, with significant impact on behaviour noted in some primary studies only. ${ }^{162838}$ One review noted that intervention 
benefit appeared to be greater where behavioural change was more pronounced and suggested that a relatively long intervention duration may be requisite for sustained behaviour change and sustained intervention impact on clinical parameters. ${ }^{28}$

\section{Adiposity}

Ten reviews considered measures of adiposity, which included weight change (seven reviews: six meta-analyses, one narrative synthesis), BMI (three reviews: two meta-analyses, one narrative synthesis), waist circumference and waist-hip ratio (one meta-analysis related to each) and body composition generally (two narrative syntheses) (see table 4). The six meta-analyses considering net weight difference associated with intervention at 1-2 years follow-up all suggested significant intervention effect, of $\sim 1-3 \mathrm{~kg}$ where reported in absolute terms (five studies). The associated narrative synthesis indicated that weight tended to be regained postend of intervention and that in the one case this did not occur (the DPS); this may have been attributable to relatively long intervention duration (4 years). ${ }^{28}$

BMI analysis outcomes were in keeping with the weight change results, with meta-analyses reporting significant net loss of $\sim 1.1-1.3 \mathrm{~kg} / \mathrm{m}^{2}$ associated with intervention, and narrative synthesis also favouring intervention and noting a small effect size. Significant intervention effect was observed for waist circumference $(-4.6 \mathrm{~cm} ; 95 \%$ CI -5.8 to -3.4$)$, whereas none was observed for waist-hip ratio $(-0.01,-0.02$ to 0.01$)$, but these analyses drew on only two and four primary studies, respectively. ${ }^{16}{ }^{36}$ Two narrative syntheses were excluded from sensitivity analysis based on AMSTAR scores, and this had little impact on the generally consistent results.

\section{Microvascular disease}

Little evidence related to microvascular disease was identified (see table 4). Two reviews (both with AMSTAR scores $>7$ ) noted that only the Da Qing study had considered this and had reported associations between the intervention and protection against retinopathy (but not nephropathy or neuropathy), at 20-year follow-up. ${ }^{27} 38$ However, these findings were reportedly limited by loss-to-follow-up and limited use of formal retinal examinations. $^{38}$

\section{Macrovascular disease}

Five reviews provided narrative reports of intervention effect on cardiovascular disease including cardiovascular mortality (see table 4). Four reviews considered two primary studies each (the Da Qing study and DPP, DPS or IDPP). ${ }^{27} 313840$ No intervention effect on events and/ or mortality was observed at the 6-year or 20-year follow-up of the Da Qing study, 3-year follow-up of the DPS or IDPP or 2.8-year DPP follow-up. An impact of the Da Qing study on cardiovascular mortality was observed for women only at 23-years follow-up. The fifth review concluded generally that cardiovascular disease outcomes at long durations of follow-up were disappointing. ${ }^{28}$ Only one review was excluded in sensitivity analysis. ${ }^{40}$

\section{Quality-adjusted life years}

Quality-adjusted life years were considered in one review only, and no relevant primary studies were identified (see table 4$){ }^{40}$

\section{All-cause mortality}

Four reviews considered all-cause mortality, drawing on data from the Da Qing study, DPP, DPS, IDPP and a regional UK-based study (Oldroyd et al, 2006) (see table 4). ${ }^{27} \quad 31 \quad 36 \quad 40 \quad 42 \quad$ A meta-analysis of the 10-year follow-up DPS data, 20-year follow-up Da Qing study data, 2.8-year follow-up DPP data and 2.8-year follow-up IDPP data indicated no intervention effect on mortality. ${ }^{31}$ Again intervention effect was only observed for women at the 23-year follow-up of the Da Qing study (HR $0.71,95 \%$ CI 0.51 to 0.99 ). ${ }^{27}$

\section{Subgroup outcomes \\ Age}

Six reviews considered the impact of age on intervention effect on incident diabetes (see table 5). Meta-regression was undertaken in three reviews (using data from 4, 11 and 18 studies, respectively). ${ }^{25} 32{ }^{33}$ None observed an age effect. One narrative report indicated that significant within-study age-effects were observed for the DPP and DPS (greater intervention effect among older age groups). ${ }^{27}$ This DPP effect was not reported in a fifth review that considered the DPP only, but this review was excluded from sensitivity analysis in view of its AMSTAR score of $4 .{ }^{37}$

Two reviews considered the impact of age on continuous measures of glycaemia. No effect was observed in a meta-regression considering impact on fasting glucose (involving data from 14 primary studies) or 2h-OGT (10 studies). ${ }^{25}$ However, stratified analysis of pooled data from 12 studies suggested no effect of intervention in those aged $40-55$ years, but a significant effect among those $\geq 55$ years, with effect size $=-0.19 \mathrm{mmol} / \mathrm{L}(95 \%$ CI -0.2 to -0.15$){ }^{41}$

\section{Gender}

Four reviews investigated the impact of gender on incident diabetes (see table 5). ${ }^{25} 272937$ One considered four primary studies and noted no gender differences in either 1-year or 2-year follow-up meta-analysis results. ${ }^{29}$ In contrast, analysis of data from 19 studies in a second review suggested that each 1-unit increase in study-level baseline percentage of men was associated with a $3 \%$ higher diabetes incidence. ${ }^{25}$ Two narrative reviews (one excluded from sensitivity analysis) reported on withinstudy gender differences only, and no differences were observed in the two primary studies discussed. ${ }^{27} 37$

No gender impact was observed when continuous measures of glycaemia were considered (two reviews). ${ }^{25}$ Review of pooled individual-level data from 
Table 4 Secondary outcomes

\begin{tabular}{lll}
\hline $\begin{array}{l}\text { Author, publication } \\
\text { date }\end{array}$ & $\begin{array}{l}\text { Number of studies } \\
\text { included in synthesis }\end{array}$ & Outcomes
\end{tabular}

Dietary and physical activity behaviours

Cardona-Morrell, 3 studies

2010

Gillett, 2012

8 studies

Schellenberg, $2013 \quad 4$ studies

Measures of adiposity

Ashra, 2015

20 studies

Baker, 2011

6 studies

Balk, 2015

24 studies

Cardonna-Morrell, $\quad 4$ studies

2010

2 studies

Gillett, 2012

5 systematic reviews, 9 RCTs

Glechner, 2015

3 studies

Norris, 2005

6 studies

Orozco, 2008

7 studies
$3 / 12$ studies reviewed reported on changes in fat and fibre intake. Substantial improvements demonstrated in one trial only, which reported half the participants meeting fibre and total fat intake goals, and a third achieving saturated fat goal.

Authors concluded that adherence to lifestyle measures could be problematic and that compliance was variable. Noted that benefits of intervention greatest among those with the highest compliance and highest lifestyle target achievement. In one study (the DPS), ${ }^{1}$ strong inverse correlation between progression to diabetes and achievement of lifestyle targets noted. Suggested that relatively long duration of intervention (eg, 4 years of DPS) potentially necessary for lasting intervention impact.

Authors concluded that most studies reported positive effects on physical activity and dietary intake. However, results not always statistically or clinically significant or sustained after end of active intervention.

Pooled mean weight difference observed in intervention, cf. control arms of $20 \mathrm{RCTs}$ at $12-18$ months $=-1.57 \mathrm{~kg}(95 \% \mathrm{Cl}-2.28$ to -0.86$)$.

Weight change difference at $>18$ months $(n=11$ RCTs $)=-1.26 \mathrm{~kg}(-2.35$ to -0.18 ).

In the 6/7 studies for which impact on BMI could be calculated, endline $B M I$ differences between intervention and control conditions consistently favoured the intervention, but effect sizes were small: range $-0.05 \mathrm{~kg} /$ $\mathrm{m}^{2}$ (observed in IDPP) to $-0.43 \mathrm{~kg} / \mathrm{m}^{2}$ (observed in VIP). No tests for differences between conditions reported.

All studies observed net weight loss associated with intervention, of between $0.2 \%$ and $10.5 \%$ of initial body weight (summary net change= $-2.2 \%, 95 \% \mathrm{Cl}-2.9$ to -1.4 )

Meta-analysis outcomes suggest significant mean weight loss at 12 months associated with intervention: summary difference $=-1.82 \mathrm{~kg}$ (95\% Cl -2.7 to -0.99$)$

Pooled mean waist circumference measurement reduction significantly greater in treated vs control groups: mean difference $=-4.6 \mathrm{~cm}(-5.8$ to $-3.4)$

No summary weight change outcomes reported, but authors note that there was a tendency for weight to be regained soon after end of intervention. This did not occur in one study (DPS), and it was hypothesised that the duration of intervention (DPS $=4$ years) may be relevant to persistence of weight change.

Meta-analysis results suggest net mean weight difference associated with intervention, cf. control condition at 1 year $=-2.44 \mathrm{~kg}(95 \% \mathrm{Cl}-3.45$ to -1.43 ). Results consistent at 3 years: net weight difference $=-2.45 \mathrm{~kg}$ $(-3.56$ to -1.33$)$.

At 1-year follow-up, the pooled estimate from four studies suggested additional weight loss of $2.8 \mathrm{~kg}(95 \% \mathrm{Cl} 4.7$ to 1.0$)$ in intervention, cf. control scenario, and net difference in BMI (three studies) $=-1.3 \mathrm{~kg} / \mathrm{m}^{2}$ $(-1.9$ to -0.8$)$. At two-year follow-up, the net weight difference associated with intervention, cf. control scenario $=-2.6 \mathrm{~kg}(-3.3$ to -1.9 ; 3 studies).

Meta-analysis results suggested net $\mathrm{BMI}$ reduction associated with intervention $=-1.1 \mathrm{~kg} / \mathrm{m}^{2}(95 \% \mathrm{Cl}-2.0$ to $-0.2 ; 6$ studies $)$. Results for weight also indicated additional weight loss in the intervention group: summary net change $=-2.7 \mathrm{~kg}(-4.7$ to $-0.7 ; 7$ studies $)$. No significant between-group difference observed for waist-hip ratio: summary difference $=-0.01$ ( -0.02 to $0.01 ; 4$ studies $)$. 
Table 4 Continued

\begin{tabular}{|c|c|c|}
\hline $\begin{array}{l}\text { Author, publication } \\
\text { date }\end{array}$ & $\begin{array}{l}\text { Number of studies } \\
\text { included in synthesis }\end{array}$ & Outcomes \\
\hline Schellenberg, 2013 & 8 studies & $\begin{array}{l}\text { Authors state that most studies reported positive effects on body } \\
\text { composition. However, results not always significant or sustained after } \\
\text { end of active intervention. }\end{array}$ \\
\hline Yoon, 2013 & 5 studies & $\begin{array}{l}\text { Two studies showed significant reduction in BMI associated with } \\
\text { intervention, cf. control scenario (SLIM study: }-0.36 \pm 1.47 \mathrm{~kg} / \mathrm{m}^{2} \text { in the } \\
\text { intervention group, } 0.08 \pm 1.80 \text { in the control group, } p=0.014 ; \mathrm{DPS} \text { study: } \\
-1.3 \pm 1.9 \mathrm{~kg} / \mathrm{m}^{2} \text { in the intervention group, }-0.3 \pm 2.0 \text { in the control group, } \\
p=<0.0001 \text { ). In these and two further studies, significant weight loss } \\
\text { observed in intervention groups in preintervention and postintervention } \\
\text { comparisons. Significant weight increase observed in intervention and } \\
\text { control groups of IDPP, but further details not reported. }\end{array}$ \\
\hline
\end{tabular}

Microvascular disease

Balk, $2015 \quad 1$ study

The Da Qing study reported a reduction in severe retinopathy at 20-year follow-up associated with intervention, cf. control condition ( $\mathrm{HR}=0.53$, $95 \% \mathrm{Cl} 0.29$ to 0.99 ). Limited evidence suggested no significant effects on nephropathy or neuropathy.

Schellenberg, $2013 \quad 1$ study

The Da Qing study reported no effect on nephropathy or neuropathy at 20 -year follow-up. However, incidence of severe retinopathy was $47 \%$ lower in intervention, cf. control participants. Authors commented that loss to follow-up was high and that many participants did not have formal retinal examinations. Hence, they considered the strength of evidence insufficient to draw conclusions.

Macrovascular disease

Balk, 2015

2 studies

Authors commented that there was no consistent pattern in cardiovascular mortality outcomes. The Da Qing study observed no difference at 20 -year follow-up (HR $0.83 ; 95 \% \mathrm{Cl} 0.48$ to 1.40$)$. In the DPP, no significant effect on cardiovascular mortality was observed at 3-year follow-up (RR 0.50; 0.09 to 2.73).

$\begin{array}{ll}\text { Gillett, } 2012 & 4 \text { studies } \\ \text { Hopper, } 2011 & 2 \text { studies }\end{array}$ Authors concluded that studies with long durations of follow-up demonstrated disappointing CVD outcomes.

Non-significant trend towards reduction in cardiovascular mortality in meta-analysis of Da Qing study (20-year follow-up) and DPP (2.8-year follow-up) studies (RR $0.70,95 \% \mathrm{Cl} 0.46$ to 1.07 ).

Schellenberg, $2013 \quad 2$ studies No differences in CVD event rates between intervention and control groups noted at 10 -year follow-up of DPS $(\mathrm{RR}=1.02,95 \% \mathrm{Cl} 0.73$ to 1.42), or the 6-year or 20-year follow-ups of the Da Qing study (at 6-year follow-up, $\mathrm{HR}=0.96 ; 0.76$ to 1.44 ; at 20 years, $\mathrm{HR}=0.98,0.71$ to 1.37). Authors conclude that strength of evidence is insufficient to determine whether lifestyle interventions impact on CVD event rates.

Yoon, 2013 studies No differences in CVD event or mortality rates between intervention and control groups noted at 20-year follow-up of Da Qing study (for event rates, $H R=0.98 ; 95 \% \mathrm{Cl} 0.71$ to 1.37 ; for mortality rates, $H R=0.83,0.48$ to 1.40). Only small number of CVD events observed at the three-year follow-up of the IDPP ( $n=4$ in the intervention group, 2 in the control group).

Quality-adjusted life years

Yoon, 2013

0 studies

All-cause mortality

Balk, 2015

3 studies

Hopper, 2011

4 studies

\section{Investigated and noted that no primary study reported on} quality-adjusted life years.

The 23-year follow-up data from the Da Qing study were indicative of lower risk of mortality in the intervention vs control arms (HR=0.71; 95\% $\mathrm{Cl} 0.51$ to 0.99 ). This effect was restricted to women and not significant at earlier time points. No similar effect was observed at the 20 -year follow-up or for men. No impact on all-cause mortality was observed at the 3-year follow-up of the DPP or 10-year follow-up of the DPS.

No impact of lifestyle intervention on all-cause mortality observed in meta-analysis (RR $0.81,95 \% \mathrm{Cl} 0.61$ to 1.09 ). (Studies 
Table 4 Continued

\begin{tabular}{|c|c|c|}
\hline $\begin{array}{l}\text { Author, publication } \\
\text { date }\end{array}$ & $\begin{array}{l}\text { Number of studies } \\
\text { included in synthesis }\end{array}$ & Outcomes \\
\hline & & $\begin{array}{l}\text { considered=DPS } 10 \text {-year follow-up, Da Qing study } 20 \text {-year follow-up, } \\
\text { DPP 2.8-year follow-up, IDPP 2.5-year follow-up). }\end{array}$ \\
\hline Orozco, 2008 & 4 studies & $\begin{array}{l}\text { Authors commented that all-cause mortality rates were comparable } \\
\text { between the intervention and control groups. (Studies considered=Da } \\
\text { Qing study 6-year follow-up, DPP 2.8-year follow-up, IDPP 2.5-year } \\
\text { follow-up and the 2-year follow-up of a regional UK-based study). }\end{array}$ \\
\hline Yoon, 2013 & 1 study & $\begin{array}{l}\text { Of studies reviewed, only the Da Qing study reported on mortality rate. } \\
\text { No significant difference in overall mortality rate between the } \\
\text { intervention and control group observed at 20-year follow-up (HR 0.96, } \\
95 \% \mathrm{Cl} 0.65 \text { to 1.41). }\end{array}$ \\
\hline
\end{tabular}

Results relating to secondary outcomes are listed for each review, as relevant, alongside the number of primary studies drawn on in the associated syntheses. Italicised entries are those assigned AMSTAR scores $<8$, excluded from sensitivity analyses.

BMI, body mass index; CVD, cardiovascular disease; DPP, Diabetes Prevention Programme; DPS, Diabetes Prevention Study; DPS, Diabetes Prevention Study; IDPP, Indian Diabetes Prevention Programme; RCT, randomised controlled trial; RR, relative risk; VIP,

Vasterbotten Intervention Programme.

three primary studies suggested no impact of gender on weight outcomes, ${ }^{29}$ but again a study-level review suggested that each percentage increase in the proportion of male participants was borderline significantly associated with $0.05 \mathrm{~kg}$ net weight gain. ${ }^{25}$

As above, one study noted the differential morbidity outcomes among men and women at the 23-year follow-up of the Da Qing study. ${ }^{39}$ The authors commented that lower intervention compliance among men may be relevant.

\section{Ethnicity}

Few data relating to effect of ethnicity were identified (see table 5). Two studies (one with AMSTAR score <8) noted only that the DPP identified no differences in incident diabetes by ethnicity. ${ }^{27}{ }^{37}$ One review of 13 primary studies noted that the percentage of non-white participants was not associated with diabetes incidence, weight change or glycaemia, at study level. ${ }^{25} \mathrm{~A}$ fourth review (with AMSTAR score $<8$ ) considered Asian participants only and noted that lifestyle interventions were associated with lower progression to diabetes in this population. $^{34}$

\section{Nature of trial}

As mentioned above, most (13/19) reviews considered RCTs only, and in the remaining reviews, RCTs contributed most of the data considered. Consideration of efficacy versus effectiveness was therefore not possible, but one review included 'translational' studies only (whether RCT or not), and this was the only review to find no impact of lifestyle intervention on glycaemia. ${ }^{16}$ It was required that the interventions considered in the primary studies of this review were all delivered in routine clinical practice settings. They were of relatively short duration (1-48 months, median 32 weeks), and the studies also had relatively short-term follow-up (460 months, median 12 months). The authors of this review noted that intervention duration could be a mediator of intervention effect, and another review similarly suggested that intervention duration could be relevant to durability of effect.

\section{DISCUSSION}

\section{Principal findings}

We aimed to provide an overview of systematic reviews of the clinical effectiveness of lifestyle interventions for those at high risk of diabetes and identified 19 reviews that met our inclusion criteria. The data considered within these reviews were largely from explanatory trials, and it was clearly demonstrated that lifestyle interventions can positively impact on diabetes incidence, although the size of effect on continuous measures of glycaemia was modest. Consistent impact on weight outcomes was also apparent, but one narrative synthesis noted that weight tended to start to be regained after the end of the intervention. There was also a suggestion that this weight regain could be avoided if the intervention was sufficiently lengthy (4 years in the example given). ${ }^{28}$ Relatively few behavioural outcome data were available, but these suggested that intervention effect on dietary and physical activity behaviours was more variable. $^{16} 2838$ There were also indications that behaviour change was associated with intervention effect on clinical parameters, and again it was suggested that the duration of intervention may be important for sustained impact on behaviour and therefore clinical outcomes. ${ }^{28}$ Very few data were available for the additional outcomes considered: microvascular and macrovascular disease, quality-adjusted life years and cardiovascular and allcause mortality. There was some evidence that the unusually long duration (6-year) intervention assessed in the Da Qing Study impacted on the cardiovascular and all-cause morality of women, at 23-year (but not 20-year) follow-up. This intervention also appeared to impact on retinopathy at 20 years. However, there are some concerns about these retinopathy data, ${ }^{38}$ and the reviews 
Table 5 Subgroup outcomes

\begin{tabular}{|c|c|c|}
\hline Author, publication date & $\begin{array}{l}\text { Number of studies } \\
\text { included in synthesis }\end{array}$ & Outcomes \\
\hline \multicolumn{3}{|l|}{ Age } \\
\hline Ashra, 2015 & 18 studies & $\begin{array}{l}\text { Meta-regression using data from } 18 \text { RCTs suggested study-level } \\
\text { mean age did not impact on T2DM incidence, weight, glycaemia } \\
\text { FPG and OGT (number of studies relevant to each outcome } \\
\text { unclear). Similarly, study age-based inclusion criteria were not found } \\
\text { to be associated with outcomes. }\end{array}$ \\
\hline Balk, 2015 & 2 studies & $\begin{array}{l}\text { Age effect considered for incident diabetes only. Discussion based } \\
\text { on reported within-study subgroup analyses. Noted that DPP and } \\
\text { DPS reported intervention had significantly greater impact on } \\
\text { diabetes incidence in older age groups. }\end{array}$ \\
\hline $\begin{array}{l}\text { Merlotti, Morabito and } \\
\text { Pontiroli, } 2014\end{array}$ & 11 studies & $\begin{array}{l}\text { In meta-regression using data from lifestyle intervention studies, no } \\
\text { significant impact of age on cumulative incidence of diabetes } \\
\text { observed. }\end{array}$ \\
\hline $\begin{array}{l}\text { Merlotti, Morabito, Ceriani } \\
\text { and Pontiroli, } 2014\end{array}$ & 4 studies & $\begin{array}{l}\text { In meta-regression using data from lifestyle intervention studies, no } \\
\text { significant impact of age on cumulative incidence of diabetes } \\
\text { observed. }\end{array}$ \\
\hline Santaguida, 2005 & 1 study & $\begin{array}{l}\text { The DPP study found no effect of age on the efficacy of the } \\
\text { intervention in reducing progression to diabetes. }\end{array}$ \\
\hline Zheng, 2015 & 12 studies & $\begin{array}{l}\text { In a stratified analysis of groups } 40-55 \text { and } \geq 55 \text { years, no significant } \\
\text { net effect on } \mathrm{FPG} \text { observed in younger group (mean difference }= \\
-0.27 \mathrm{mmol} / \mathrm{L}, 95 \% \mathrm{Cl}-0.60 \text { to } 0.05 \text { ). Effect observed for } \\
\geq 55 \text { years group (mean difference }=-0.19 \mathrm{mmol} / \mathrm{L},-0.22 \text { to }-0.15 \text {, } \\
\mathrm{p}<0.05 \text { ). }\end{array}$ \\
\hline
\end{tabular}

Gender

Ashra, 2015

19 studies

Balk, 2015

2 studies

Glechner, 2015
4 studies

3 studies

3 studies
A 1 unit increase in study-level baseline percentage of males was associated with a $3 \%$ higher incidence of T2DM $(p=0.022)$, and borderline significantly associated with $0.05 \mathrm{~kg}$ weight gain $(p=0.054)$, in those receiving intervention, cf. usual care. No impact on glycaemia observed.

Sex differences considered for incident diabetes only. Discussion based on reported within-study subgroup analyses. Noted that sex differences investigated within DPP and DPS, but no significant effect on diabetes incidence detected.

Meta-analysis results for diabetes incidence at 1 year: for men, $\mathrm{RR}=0.53$ (95\% $\mathrm{Cl} 0.26$ to 1.10$)$; for women, $\mathrm{RR}=0.71$ (0.31 to 1.64$)$; no difference by gender $(p=0.61)$. Similar results at 3 years: for men $R R=0.70$ (0.53 to 0.91); for women $R R=0.51$ ( 0.35 to 0.75 ); no difference by gender $(\mathrm{p}=0.20)$. Da Qing study had the longest follow-up (6 years) and detected no significant difference in impact of intervention, between men and women.

In meta-analysis of body weight outcomes: similar additional mean weight reductions associated with intervention observed for males and females at 1 year $(-2.29 \mathrm{~kg}(-5.22$ to -0.76$)$ and $-2.65 \mathrm{~kg}$ $(-4.23$ to -1.07$)$, respectively; $p=0.74)$. At 3 years, additional mean weight reduction associated with intervention was $-2.78 \mathrm{~kg}(-4.00$ to -1.57$)$ for males, and $-0.6 \mathrm{~kg}(-3.43$ to 2.24$)$ for females; $\mathrm{p}=0.16$.

In meta-analysis of glycaemia outcomes: at 1 year, males and females had similar mean reductions in FPG and $2 \mathrm{~h}-\mathrm{OGT}$ associated with intervention (for FPG, mean difference $=$ $-0.45 \mathrm{mmol} / \mathrm{L}(-1.10$ to 0.19$)$ and $-0.26 \mathrm{mmol} / \mathrm{L}(-0.46$ to -0.06$)$, respectively; $\mathrm{p}=0.57$; for $2 \mathrm{~h}-\mathrm{OGT}$, mean difference $=-0.77 \mathrm{mmol} / \mathrm{L}$ $(-1.55$ to 0.01$)$ and $-0.56 \mathrm{mmol} / \mathrm{L}(-1.12$ to 0.00$)$, respectively; $\mathrm{p}=0.67$ ). Three-year follow-up outcomes were similar: for FPG, mean difference $=-0.40 \mathrm{mmol} / \mathrm{L}(-0.58$ to -0.21$)$ and $-0.08 \mathrm{mmol} / \mathrm{L}$ $(-0.39$ to 0.24$)$, for males and females, respectively, $p=0.09$; for $2 \mathrm{~h}$-OGT, mean difference $=-0.78 \mathrm{mmol} / \mathrm{L}(-1.33$ to 0.24$)$ and $-0.62 \mathrm{mmol} / \mathrm{L}(-1.07$ to -0.17$)$, respectively, $\mathrm{p}=0.65$. 
Table 5 Continued

\begin{tabular}{|c|c|c|}
\hline Author, publication date & $\begin{array}{l}\text { Number of studies } \\
\text { included in synthesis }\end{array}$ & Outcomes \\
\hline Santiguida, 2005 & 1 study & $\begin{array}{l}\text { The DPP study found no effect of sex on the efficacy of intervention } \\
\text { in reducing progression to diabetes. }\end{array}$ \\
\hline Selph, 2015 & 1 study & $\begin{array}{l}\text { Noted that the Da Qing study detected significantly lower risk of } \\
\text { all-cause mortality (HR } 0.71 ; 95 \% \mathrm{Cl} 0.51 \text { to } 0.99 \text { ) and CVD } \\
\text { mortality (HR 0.59; } 0.36 \text { to } 0.96 \text { ) among intervention vs control } \\
\text { participants, for females only, at } 23 \text {-year follow-up. No significant } \\
\text { effect of intervention observed among males. No clear explanation } \\
\text { for disparity, but hypothesised potentially due to relatively poor } \\
\text { compliance among males. }\end{array}$ \\
\hline \multicolumn{3}{|r|}{ 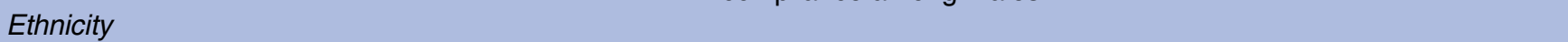 } \\
\hline Ashra, 2015 & 13 studies & $\begin{array}{l}\text { Study-level percentage of non-white participants not significantly } \\
\text { associated with incidence of T2DM, weight change or glycaemia. }\end{array}$ \\
\hline Balk, 2015 & 1 study & $\begin{array}{l}\text { Discussion based on reported within-study subgroup analyses. } \\
\text { Noted that differences by ethnicity considered in DPP, and no } \\
\text { significant difference in effect of intervention detected. }\end{array}$ \\
\hline Modesti , 2016 & 8 studies & $\begin{array}{l}\text { Meta-analysis demonstrated lower rates of incident diabetes among } \\
\text { Asian participants assigned to intervention, cf. control condition: } \\
\text { OR=0.55; } 95 \% \mathrm{Cl} 0.44 \text { to } 0.70 \text {. No participants of other ethnic } \\
\text { backgrounds reviewed. }\end{array}$ \\
\hline Santaguida, 2005 & 1 study & $\begin{array}{l}\text { Noted that the DPP study found no effect of ethnicity on the efficacy } \\
\text { of intervention in reducing the progression to diabetes. }\end{array}$ \\
\hline
\end{tabular}

considered suggested no impact on cardiovascular disease or mortality has been observed in any other trial to-date. Only a minority of reviews considered subgroups. Most synthesis outcomes suggested no impact of age on diabetes incidence or other measures of glycaemia, but there were reports of within-study effects of age within the DPP and DPS ${ }^{27}$ and an age effect on continuous measures of glycaemia in a stratified analysis. ${ }^{41}$ In all cases greater intervention impact was reported for higher age groups. In analyses of individual-level data, no effect of gender was observed for diabetes incidence, other measures of glycaemia or weight. There were no obvious indications of an effect of ethnicity, but this had been very little considered.

\section{Strengths and weaknesses of study}

We carried out a wide, thorough and systematic search for relevant information and identified a large number of reviews for consideration, most of which were recent. However, there are several limitations of overviews that are relevant here, including the representation of primary studies in more than one review, and the reliance on individual review methodologies, with associated inability to consider the quality of the primary studies in detail, or study outcomes not investigated in the reviews themselves. In particular, there were few data available regarding subgroups. There was also limited availability of vascular end point data, linked to the short-term follow-up in most primary studies. We have not systematically searched for more recent primary studies not included in the reviews considered here. However, the latest update from the DPP is in keeping with the results reviewed, ${ }^{43}$ as are the results of additional recent trials, ${ }^{44} 45$ including trials based in routine practice, where clinical benefits were found to be modest. ${ }^{46} 47$ We excluded non-English language publications that we were unable to access (see figure 1). Whether these studies would otherwise have met our inclusion criteria is unclear.

\section{Findings in relation to previous work}

Concern about the potentially limited impact of lifestyle interventions for the population with intermediate hyperglycaemia, on vascular disease and mortality end points, has been raised previously, ${ }^{48-51}$ particularly as these outcomes are likely to be those that most trouble patients and account for most of the direct health costs associated with diabetes treatment. ${ }^{52}$ Although data related to these outcomes are limited, they are derived from trials with the longest and most intensive interventions and relatively long durations of follow-up. It is therefore unlikely that impact on these outcomes would be observed following shorter interventions delivered in more routine care environments (ie, interventions more likely to be applied in practice), given that the relative impact of such interventions on intermediate outcomes is low and perhaps more transient. ${ }^{1628}$ Similarly transient effect of behaviour change interventions has been 
observed in the context of overweight/obesity management per se, even at reasonably short-term follow-up. ${ }^{5354}$ Additional reasons to be cautious generalising outcomes from explanatory behaviour change trials to those achievable in routine practice include the likely relatively high motivation of trial participants and the typical intervention resourcing and fidelity achieved in trials versus routine practice settings. ${ }^{55}$ Population-level impact would also require that sufficient numbers of individuals eligible to access the intervention are identified, offered the intervention, and choose to participate. In many settings, new resources would be required to identify relevant patients for a lifestyle intervention programme, and few data regarding intervention uptake are available to-date. There has similarly been little investigation into potentially negative aspects of such interventions. For example, there is the potential for participant disengagement-both with the specific intervention and lifestyle change more generally-if anticipated programme outcomes are difficult to achieve and/or maintain. $^{56}$ The possibility of staff disengagement has been raised previously. ${ }^{57}$

\section{Implications for future research, policy and practice}

Despite the lack of demonstrated effectiveness of lifestyle interventions for diabetes prevention-and apparent modest impact on outcomes of interest even under trial conditions - the option of population-wide intervention roll-out is currently being discussed in several countries. NHS England has recently started to implement a programme across England, but so far as we are aware, no other country has adopted a national programme as yet, perhaps due to the outstanding clinical and costeffectiveness concerns. Cost-effectiveness remains a concern as to-date cost-effectiveness studies have been reliant on data from the studies reviewed above and thus subject to the attendant limitations. Cost-effectiveness studies have also typically not factored-in costs for associated requisite activities such as diabetes risk-assessment services, which the WHO has warned could overwhelm primary care. ${ }^{4}$ Rigorous evaluation of any programme that is implemented could help address the evidence gap relating to effectiveness of DPPs.

In view of the anticipated limited impact of lifestyle interventions for diabetes prevention on diabetes and cardiovascular disease risk burdens, many have recently commented that a broader approach to these issues is overdue. ${ }^{50} 5158$ National and international guidance and policy documents have for many years advocated for relevant environmental change through widespread actions across many policy domains and associated legislative and fiscal commitment. ${ }^{4859}$ For example, action on information, marketing and pricing for tobacco, food and alcohol has been recommended, as well as sensitivity to the health impacts of agriculture, transport, education and urban planning policy. There is good evidence to support some of these wider policy options that would reduce the accessibility of products and lifestyles associated with overweight/obesity, diabetes and cardiovascular risk and promote access to the opposite. ${ }^{61-63}$ Renewed focus on such options may be useful.

\section{CONCLUSIONS}

There have been many recent systematic reviews of DPPs, consistently demonstrative that lifestyle interventions for populations at high diabetes risk can reduce or delay risk of progression to diabetes. However, the reviewed data are overwhelmingly from RCTs. Where intervention duration and setting have been considered, outcomes from shorter interventions in routine practice settings appear more variable. In keeping with this, recent in-practice trials have achieved modest results. Some countries are considering national roll-out of lifestyle interventions for diabetes prevention. Thorough and early evaluation of any such programme would be useful. Additional approaches will be required if we are to impact on the global diabetes burden.

Acknowledgements The Department of Primary Care \& Public Health at Imperial College London is grateful for support from the NW London NIHR Collaboration for Leadership in Applied Health Research \& Care, the Imperial NIHR Biomedical Research Centre and the Imperial Centre for Patient Safety and Service Quality. The views expressed in this publication are those of the authors.

Contributors BM and AJM performed the searches and selection. LH and BM carried out data extraction, quality assessment and syntheses. AJM drafted the manuscript. All authors reviewed and edited the manuscript, and all approved the final draft.

Competing interests None declared.

Provenance and peer review Not commissioned; externally peer reviewed.

Data sharing statement Full data set available from the corresponding author on reasonable request.

Open Access This is an Open Access article distributed in accordance with the terms of the Creative Commons Attribution (CC BY 4.0) license, which permits others to distribute, remix, adapt and build upon this work, for commercial use, provided the original work is properly cited. See: http:// creativecommons.org/licenses/by/4.0/

\section{REFERENCES}

1. Stevens JW, Khunti K, Harvey R, et al. Preventing the progression to type 2 diabetes mellitus in adults at high risk: a systematic review and network meta-analysis of lifestyle, pharmacological and surgical interventions. Diabetes Res Clin Pract 2015;107:320-31.

2. Public Health England. Adult obesity and type 2 diabetes. PHE, 2014. https://www.gov.uk/government/uploads/system/uploads/ attachment_data/file/338934/Adult_obesity_and_type_2_diabetes_. pdf (accessed Dec 2015).

3. Tillin T, Hughes AD, Godsland IF, et al. Insulin resistance and truncal obesity as important determinants of the greater incidence of diabetes in Indian Asians and African Caribbeans Compared With Europeans: the Southall And Brent REvisited (SABRE) cohort. Diabetes Care 2013;36:383-93.

4. World Health Organization. Global report on diabetes. Geneva: WHO Press, 2016.

5. Whiting DR, Guariguata L, Weil C, et al. IDF diabetes atlas: global estimates of the prevalence of diabetes for 2011 and 2030. Diabetes Res Clin Pract 2011;94:311-21.

6. da Rocha Fernandes J, Ogurtsova K, Linnenkamp U, et al. IDF diabetes atlas estimates of 2014 global health expenditures on diabetes. Diabetes Res Clin Pract 2016;117:48-54.

7. National Cardiovascular Intelligence Network, Public Health England. Diabetes prevalence model for local authorities and CCGs. 
NCIN, 2012. http://www.yhpho.org.uk/resource/view.aspx? $\mathrm{RID}=154049$ (accessed Dec 2015).

8. NHS England. Five year forward view. NHS England, 2014. https:// www.england.nhs.uk/wp-content/uploads/2014/10/5yfv-web.pdf (accessed Dec 2015).

9. 111th Congress (2009-10). Diabetes Prevention Act of 2009. House of Representatives, 2009. https://www.congress.gov/bill/ 111th-congress/house-bill/4124/text (accessed Sep 2016)

10. Schwarz PE, Gruhl U, Bornstein SR, et al. The European Perspective on Diabetes Prevention: development and implementation of a European Guideline and training standards for diabetes prevention (IMAGE). Diab Vasc Dis Res 2007;4:353-7.

11. Lindahl B, Nilssön TK, Borch-Johnsen $\mathrm{K}$, et al. A randomized lifestyle intervention with 5-year follow-up in subjects with impaired glucose tolerance: pronounced short-term impact but long-term adherence problems. Scand J Public Health 2009;37:434-42.

12. Diabetes Prevention Program Research GroupKnowler WC, Fowler SE, Hamman RF, et al. 10-year follow-up of diabetes incidence and weight loss in the Diabetes Prevention Program Outcomes Study. Lancet 2009;374:1677-86.

13. Ramachandran A, Snehalatha C, Mary S, et al. The Indian Diabetes Prevention Programme shows that lifestyle modification and metformin prevent type 2 diabetes in Asian Indian subjects with impaired glucose tolerance (IDPP-1). Diabetologia 2006;49:289-97.

14. Roumen C, Feskens EJM, Corpeleijn E, et al. Predictors of lifestyle intervention outcome and dropout: the SLIM study. Eur J Clin Nutr 2011;65:1141-7.

15. Li G, Zhang P, Wang J, et al. Cardiovascular mortality, all-cause mortality, and diabetes incidence after lifestyle intervention for people with impaired glucose tolerance in the Da Qing Diabetes Prevention Study: a 23-year follow-up study. Lancet Diabetes Endocrinol 2014;2:474-80.

16. Cardona-Morrell M, Rychetnik L, Morrell SL, et al. Reduction of diabetes risk in routine clinical practice: are physical activity and nutrition interventions feasible and are the outcomes from reference trials replicable? A systematic review and meta-analysis. BMC Public Health 2010;10:653.

17. Uusitupa M, Peltonen M, Lindström J, et al. Ten-year mortality and cardiovascular morbidity in the Finnish diabetes prevention studysecondary analysis of the randomized trial. PLOS One 2009;4: e5656.

18. Zhuo X, Zhang P, Hoerger TJ. Lifetime direct medical costs of treating type 2 diabetes and diabetic complications. Am J Prev Med 2013;45:253-61.

19. Moher D, Liberati A, Tetzlaff J, et al. Preferred reporting items for systematic reviews and meta-analyses: the PRISMA statement. PLoS Med 2009;6:e1000097.

20. Higgins JPT, Green S, eds. Cochrane Handbook for Systematic Reviews of Interventions, Version 5.1.0 [updated March 2011]. The Cochrane Collaboration, 2011. http://www.handbook.cochrane.org (accessed Jun 2016)

21. Wilczynski NL, Haynes RB, Hedges Team. EMBASE search strategies achieved high sensitivity and specificity for retrieving methodologically sound systematic reviews. J Clin Epidemiol 2007:60:29-33.

22. Centre for Reviews and Dissemination, University of York. About DARE. CRD, 2016. http://www.crd.york.ac.uk/CRDWeb/AboutPage. asp (accessed Jun 2015).

23. Montori VM, Wilczynski NL, Morgan D, et al. the Hedges Team. Optimal search strategies for retrieving systematic reviews from MEDLINE: analytical survey. BMJ 2005;330:68.

24. Shea BJ, Grimshaw JM, Wells GA, et al. Development of AMSTAR: a measurement tool to assess the methodological quality of systematic reviews. BMC Med Res Methodol 2007;7:10.

25. Ashra NB SR, Carter P, Davies MJ, et al. A systematic review and meta-analysis assessing the effectiveness of pragmatic lifestyle interventions for the prevention of type 2 diabetes mellitus in routine practice. Public Health England, 2015. https://www.gov.uk/ government/uploads/system/uploads/attachment_data/file/456147/ PHE_Evidence_Review_of_diabetes_prevention_programmesFINAL.pdf (accessed Jun 2015).

26. Baker MK, Simpson K, Lloyd B, et al. Behavioral strategies in diabetes prevention programs: a systematic review of randomized controlled trials. Diabetes Res Clin Pract 2011:91:1-12.

27. Balk EM, Earley A, Raman G, et al. Combined diet and physical activity promotion programs to prevent type 2 diabetes among persons at increased risk: a systematic review for the community preventive services task force. Ann Intern Med 2015;163:437-51.

28. Gillett M, Royle P, Snaith A, et al. Non-pharmacological interventions to reduce the risk of diabetes in people with impaired glucose regulation: a systematic review and economic evaluation. Health Technol Assess 2012;16:1-236.

29. Glechner A, Harreiter J, Gartlehner G, et al. Sex-specific differences in diabetes prevention: a systematic review and meta-analysis. Diabetologia 2015;58:242-54.

30. Gong QH, Kang JF, Ying YY, et al. Lifestyle interventions for adults with impaired glucose tolerance: a systematic review and meta-analysis of the effects on glycemic control. Intern Med 2015;54:303-10.

31. Hopper I, Billah B, Skiba M, et al. Prevention of diabetes and reduction in major cardiovascular events in studies of subjects with prediabetes: meta-analysis of randomised controlled clinical trials. Eur J Cardiovasc Prev Rehabil 2011;18:813-23.

32. Merlotti C, Morabito A, Pontiroli AE. Prevention of type 2 diabetes; a systematic review and meta-analysis of different intervention strategies. Diabetes Obes Metab 2014;16:719-27.

33. Merlotti C, Morabito A, Ceriani V, et al. Prevention of type 2 diabetes in obese at-risk subjects: a systematic review and meta-analysis. Acta Diabetol 2014;51:853-63.

34. Modesti PA, Galanti G, Cala' P, et al. Lifestyle interventions in preventing new type 2 diabetes in Asian populations. Intern Emerg Med 2016;11:375-84

35. Norris SL, Zhang X, Avenell A, et al. Long-term non-pharmacological weight loss interventions for adults with prediabetes. Cochrane Database Syst Rev 2005;(2):CD005270.

36. Orozco LJ, Buchleitner AM, Gimenez-Perez G, et al. Exercise or exercise and diet for preventing type 2 diabetes mellitus. Cochrane Database Syst Rev 2008;(3):CD003054.

37. Santaguida PL, Balion C, Hunt D, et al. Diagnosis, prognosis, and treatment of impaired glucose tolerance and impaired fasting glucose. Evid Rep Technol Assess (Summ) 2005;128: $1-11$.

38. Schellenberg ES, Dryden DM, Vandermeer B, et al. Lifestyle interventions for patients with and at risk for type 2 diabetes: a systematic review and meta-analysis. Ann Intern Med 2013;159:543-51.

39. Selph S, Dana T, Blazina I, et al. Screening for type 2 diabetes mellitus: a systematic review for the U.S. preventive services task force. Ann Intern Med 2015;162:765-76.

40. Yoon U, Kwok LL, Magkidis A. Efficacy of lifestyle interventions in reducing diabetes incidence in patients with impaired glucose tolerance: a systematic review of randomized controlled trials. Metab Clin Exp 2013;62:303-14.

41. Zheng L, Wu J, Wang G, et al. Comparison of control fasting plasma glucose of exercise-only versus exercise-diet among a pre-diabetic population: a meta-analysis. Eur J Clin Nutr 2016;70:424-30.

42. Oldroyd JC, Unwin NC, White M, et al. Randomised controlled trial evaluating lifestyle interventions in people with impaired glucose tolerance. Diabetes Res Clin Pract 2006;72:117-27.

43. Diabetes Prevention Program Research Group. Long-term effects of lifestyle intervention or metformin on diabetes development and microvascular complications over 15-year follow-up: the Diabetes Prevention Program Outcomes Study. Lancet Diabetes Endocrinol 2015;3:866-75.

44. Van Name MA, Camp AW, Magenheimer EA, et al. Effective translation of an intensive lifestyle intervention for Hispanic women with prediabetes in a community health center setting. Diabetes Care 2016;39:525-31.

45. Nanditha A, Snehalatha C, Ram J, et al. Impact of lifestyle intervention in primary prevention of type 2 diabetes did not differ by baseline age and BMI among Asian-Indian people with impaired glucose tolerance. Diabet Med 2016, Dec;33(12): $1700-04$

46. Davies MJ, Gray LJ, Troughton J, et al. A community based primary prevention programme for type 2 diabetes integrating identification and lifestyle intervention for prevention: the let's prevent diabetes cluster randomised controlled trial. Prev Med 2016;84:48-56.

47. Vita P, Cardona-Morrell M, Bauman A, et al. Type 2 diabetes prevention in the community: 12-month outcomes from the Sydney Diabetes Prevention Program. Diabetes Res Clin Pract 2016;112:13-19.

48. Kahn R, Davidson MB. The reality of type 2 diabetes prevention. Diabetes Care 2014;37:943-9.

49. Wareham NJ. Mind the gap: efficacy versus effectiveness of lifestyle interventions to prevent diabetes. Lancet Diabetes Endocrinol 2015;3:160-1.

50. Yudkin JS, Millett C. Diabetes prevention in England. Lancet Diabetes Endocrinol 2015;3:502

51. Barry E, Roberts S, Finer S, et al. Time to question the NHS Diabetes Prevention Programme. BMJ 2015;351:h4717. 
52. Hex N, Bartlett C, Wright D, et al. Estimating the current and future costs of type 1 and type 2 diabetes in the UK, including direct health costs and indirect societal and productivity costs. Diabet Med 2012;29:855-62.

53. Curioni CC, Lourenço PM. Long-term weight loss after diet and exercise: a systematic review. Int J Obes 2005;29:1168-74.

54. Wadden TA, Butryn ML, Byrne KJ. Efficacy of lifestyle modification for long-term weight control. Obes Res 2004;12:151S-62S

55. Ioannidis JPA. Why most published research findings are false. PLoS Med 2005;2:e124.

56. Jallinoja P, Pajari P, Absetz P. Repertoires of lifestyle change and self-responsibility among participants in an intervention to prevent type 2 diabetes. Scand J Caring Sci 2008;22:455-62.

57. Yudkin JS. Re: time to question the NHS Diabetes Prevention Programme. BMJ Rapid Response 2015. http://www.bmj.com/ content/351/bmj.h4717/rapid-responses (accessed Jun 2016).

58. House of Commons Committee of Public Accounts. Management of adult diabetes services in the NHS: progress review. Seventeenth report of session 2015-16. London: The Stationary Office Limited,
2016. http://www.publications.parliament.uk/pa/cm201516/cmselect/ cmpubacc/563/563.pdf (accessed Jun 2016).

59. Wanless D. Securing good health for the whole population. Final report. London, UK: Department of Health, 2004. https://www. southampton.gov.uk/moderngov/documents/s19272/prevention-appx \%201\%20wanless\%20summary.pdf (accessed Jun 2016).

60. World Health Organization. Global action plan for the prevention and control of noncommunicable diseases 2013-2020. Geneva: WHO Press, 2013. http://apps.who.int/iris/bitstream/10665/94384/1/ 9789241506236 eng.pdf (accessed Sep 2016)

61. Pasala SK, Rao AA, Sridhar GR. Built environment and diabetes. Int $J$ Diabetes Dev Ctries 2010;30:63-8.

62. Hill J, Nielsen M, Fox MH. Understanding the social factors that contribute to diabetes: a means to informing health care and socia policies for the chronically ill. Perm J 2013;17:67-72.

63. Whiting D, Unwin N, Roglic G. Diabetes: equity and social determinants. In: Blas E, Kurup AS, eds. Equity, social determinants and public health programmes. World Health Organization, 2010:77-94. 